IZA DP No. 6841

Ethnic Segregation in Germany

Albrecht Glitz

September 2012

Forschungsinstitut zur Zukunft der Arbeit Institute for the Study of Labor 


\title{
Ethnic Segregation in Germany
}

\author{
Albrecht Glitz \\ Universitat Pompeu Fabra, \\ Barcelona GSE and IZA
}

\section{Discussion Paper No. 6841 September 2012}

\author{
IZA \\ P.O. Box 7240 \\ 53072 Bonn \\ Germany \\ Phone: +49-228-3894-0 \\ Fax: +49-228-3894-180 \\ E-mail: iza@iza.org
}

\begin{abstract}
Any opinions expressed here are those of the author(s) and not those of IZA. Research published in this series may include views on policy, but the institute itself takes no institutional policy positions.

The Institute for the Study of Labor (IZA) in Bonn is a local and virtual international research center and a place of communication between science, politics and business. IZA is an independent nonprofit organization supported by Deutsche Post Foundation. The center is associated with the University of Bonn and offers a stimulating research environment through its international network, workshops and conferences, data service, project support, research visits and doctoral program. IZA engages in (i) original and internationally competitive research in all fields of labor economics, (ii) development of policy concepts, and (iii) dissemination of research results and concepts to the interested public.
\end{abstract}

IZA Discussion Papers often represent preliminary work and are circulated to encourage discussion. Citation of such a paper should account for its provisional character. A revised version may be available directly from the author. 
IZA Discussion Paper No. 6841

September 2012

\section{ABSTRACT}

\section{Ethnic Segregation in Germany ${ }^{*}$}

This paper provides a comprehensive description of the nature and extent of ethnic segregation in Germany. Using matched employer-employee data for the universe of German workers over the period 1975 to 2008, I show that there is substantial ethnic segregation across both workplaces and residential locations and that the extent of segregation has been relatively stable over the last 30 years. Workplace segregation is particularly pronounced in agriculture and mining, construction, and the service sector, and among low-educated workers. Ethnic minority workers are segregated not only from native workers but also from workers of other ethnic groups, but less so if they share a common language. From a dynamic perspective, for given cohorts of workers, the results show a clear pattern of assimilation, reminiscent of typical earnings assimilation profiles, with immigrants being increasingly less likely to work in segregated workplaces with time spent in the host country.

JEL Classification: J61, J63, J31

Keywords: ethnic minorities, residential segregation, workplace segregation

Corresponding author:

Albrecht Glitz

Department of Economics and Business

Universitat Pompeu Fabra

Ramon Trias Fargas 25-27

08005 Barcelona

Spain

E-mail: albrecht.glitz@upf.edu

\footnotetext{
* I am greatly indebted to the IAB and, in particular, Marco Hafner for the support with the data. I would also like to thank Christian Dustmann and Uta Schönberg for helpful suggestions. Finally, I am also grateful for the support of the Barcelona GSE Research Network, the Government of Catalonia, and the Spanish Ministry of Science (Project No. ECO2008-06395-C05-01 and ECO2011-30323-C03-02).
} 


\section{Introduction}

With foreign-born individuals making up at least 10 percent of the resident population in most developed countries (see OECD, 2011), the economic integration of these immigrant populations has become a main concern for policy makers. In providing empirical analysis on this issue, economists have primarily focused on the earnings position of immigrants relative to the native population as the key indicator of their economic situation. ${ }^{1}$ In comparison and with few exceptions, segregation, both residential and in particular across workplaces, has received relatively little attention, despite being an intuitive measure of an immigrants' degree of integration in his or her host country.

In this paper, I use two widely-applied segregation measures, the index of dissimilarity and the index of co-worker/co-resident segregation, to analyse the extent of ethnic segregation in Germany. The analysis comprises both workplace and residential segregation, and documents the current situation as well as key trends over the last three decades, using administrative data that cover the universe of workers in the German labour market over the period 1975 to 2008. Most of the reported segregation indices are adjusted to account for the common issues of random segregation and segregation due to differences in ethnic group characteristics. This paper is the first such analysis for Germany, and one of the very few studies that is able to comprehensively study workplace segregation.

There are four main findings. First, there is substantial ethnic segregation between immigrants and Germans across both workplaces and residential locations. The extent of this segregation has been relatively stable over the last three decades and is particularly pronounced in agriculture and mining, construction, and the low-skill service sector. Second, low-educated workers are significantly more segregated than high-educated workers across workplaces but not residential locations. Third, immigrants are typically as segregated from immigrants of other nationalities as they are from native Germans. However, if two nationality groups speak the same language, they are more likely to work together in the same establishments. Fourth, although ethnic segregation at the workplace declines with time in the labour market, it never disappears entirely for a given immigrant arrival cohort. On the contrary, for more recent immigrant cohorts, the speed of assimilation

\footnotetext{
${ }^{1}$ For an overview of the literature studying immigrants' earnings assimilation, see Dustmann and Glitz (2011).
} 
in terms of workplace segregation has decreased significantly, a pattern also reflected in their wage assimilation profiles.

This paper adds to the wider economic literature on ethnic segregation. Most of this literature has focused on residential segregation (e.g. Iceland et al., 2002 and Cutler et al., 2008a for the United States, Clark and Drinkwater, 2002, for England and Wales, and Musterd, 2005, and Semyonov and Glikman, 2009, for a number of European countries). Early studies have provided some evidence that segregation is associated with significantly poorer economic outcomes of ethnic minority groups (see e.g. Chiswick and Miller, 1995, who focus on immigrants, and Cutler and Glaeser, 1997, who focus on blacks). More recent work, however, has challenged this view, arguing that these findings are due to non-random selection of individuals into areas (see Edin et al., 2003, Damm, 2009), and that residential segregation leads to an increase in employment probabilities and wages of minorities. ${ }^{2}$ Similar to the present study, Carrington and Troske (1998), as well as the series of papers by Hellerstein and Neumark $(2003,2008)$ and Hellerstein et al. (2007), analyse establishment-level segregation of minority groups in the United States. These papers focus on blacks and Hispanics, while I, similar to Åslund and Skans (2010), investigate establishment level segregation by ethnicity, distinguishing between various different groups of immigrants.

There are a number of theories that provide an explanation for ethnic segregation, most prominently those related to networks, consumption and productivity spillovers and discrimination. Networks may lead to a concentration of members of the same ethnic group in the same residential areas or, through the use of job referrals, the same workplaces as long as they are disproportionately based on ethnic similarity. There is ample sociological evidence for this type of homophily (e.g. McPherson et al., 2001). According to the German SOEP, 61.7 percent of immigrants name as their first befriended person another immigrant, compared to only 4.9 percent of German individuals. More importantly, out of those 61.7 percent of immigrant friends, 91.7 percent originate from the same country of origin as the respondent. ${ }^{3}$ In addition, 42.7 percent of new jobs

\footnotetext{
${ }^{2}$ In line with these findings, Munshi (2003) provides evidence that Mexicans who belong to a larger network in the U.S. are more likely to be employed and hold a higher paying non-agricultural job. Similarly, Cutler et al. (2008b) show that there are beneficial effects of segregation for immigrants in the U.S., in particular for groups with high human capital levels.

${ }^{3}$ Similar figures hold for the second and third befriended person. All figures are based on pooled observations from the 1996 and 2001 waves of the German SOEP.
} 
started by immigrants over the period 1990 to 2001 were found through acquaintances, friends and relatives, a magnitude consistent with that reported for other developed economies (see Ioannides and Loury, 2004, Pellizzari, 2010, or Topa, 2011). Thus, the exchange of information about job (and residential) opportunities within an ethnically defined network may give rise to patterns of segregation. A second possible mechanism are consumption externalities and productivity spillovers. Individuals sharing a common language and cultural background may value each others company and face lower transaction and communication costs (Lazear, 1999) that make them more productive in the workplace. As a result, individuals of the same ethnicity will tend to move into the same neighbourhoods and workplaces, and employers will prefer hiring workers with the same ethnic background. A third well-known mechanism that could lead to segregation is discrimination (see Becker, 1957). For example, if employers or landlords experience disutility from hiring or renting out to ethnic minority individuals, they will discriminate against them when making their corresponding decisions, which in turn leads to ethnically segregated workplaces and neighbourhoods. All three theories make similar empirical predictions regarding segregation patterns and it is typically difficult to distinguish between the three. While the main purpose of this paper is not to identify the main mechanism behind the observed patterns in Germany nor to assess the effect of segregation on labour market outcomes ${ }^{4}$, some of the evidence put forward can lend support or be viewed as evidence against a particular segregation mechanism.

The structure of the paper is as follows. In the next section, I provide an overview of the main immigrant groups in Germany and describe the data. In Section 3, I present the two measures of segregation used in the analysis and how these can be adjusted to take account of random segregation and differences in observable characteristics across ethnic groups. In Section 4, I discuss in detail the empirical results. Section 5 concludes.

\footnotetext{
${ }^{4}$ These issues are analysed in detail by Dustmann et al. (2011), who argue that referral-based job search networks are likely to be an important explanation for the clustering of ethnic minority workers across establishments.
} 


\section{$2 \quad$ Background and Data}

The current immigrant population in Germany essentially reflects two large immigration waves. The first wave started in the mid-1950s when, as a result of strong economic growth in (West-) Germany and a lack of available manpower, Germany started to actively recruit foreign workers abroad, predominantly in Turkey, Yugoslavia, Italy, Greece, Spain and Portugal. Following the recession in 1973/1974, this active recruitment of immigrants was abandoned. However, subsequent immigration of family members continued. The second and more recent immigration wave to Germany was triggered by the collapse of the Former Soviet Union and the political changes in Eastern Europe in the late 1980s and early 1990s. The main immigrant groups of this period were, on the one hand, ethnic German immigrants (so-called Aussiedler), mostly from Poland and the Former Soviet Union, and, on the other hand, refugees from the wars in Former Yugoslavia. ${ }^{5}$

The data I use in the empirical analysis to describe the extent of these immigrant groups' segregation come from social security records that extend over more than three decades, from 1975 to 2008. These records comprise every man and woman covered by the social security system, observed at the $30^{\text {th }}$ of June in each year. ${ }^{6}$ The data contain unique worker and establishment identifiers, as well as an unusually wide array of background characteristics, such as education ${ }^{7}$, occupation, industry, and citizenship. The citizenship variable is very detailed, and allows a distinction between, for instance, citizens of Russia, Belarus, and the Ukraine.

As in most official statistics in Germany, I assign immigrant status based on foreign citizenship, rather than place of birth. ${ }^{8}$ Arguably, the latter is a more suitable determinant but is not recorded in the administrative data. Consequently, individuals with

\footnotetext{
${ }^{5}$ For more detailed information on the different migration waves and their historical background, see Bauer et al. (2005).

${ }^{6}$ Not included are civil servants, the self-employed, and military personnel. In $2001,77.2 \%$ of all workers in the German economy were covered by social security and are hence recorded in the data (Bundesagentur für Arbeit, 2004).

${ }^{7}$ To improve the consistency of the education variable in the data, I apply the imputation algorithm suggested by Fitzenberger et al. (2006)

${ }^{8}$ Prior to 2000 , naturalization of non-German adults was only possible after 15 years of legal residence, and, following the principle of ius sanguinis, individuals born in Germany by non-German parents did not obtain German citizenship but the citizenship of their parents. Since 1 January 2000, naturalization of adults is possible after only eight years of legal residence in Germany and new born children are automatically granted German citizenship if their non-German parents have legally lived in Germany for at least eight years.
} 
foreign citizenship who were born in Germany are included among the immigrant population. However, even at the end of the observation period in 2008 , only $14.4 \%$ of all working-age foreign citizens living in Germany were also born there.

Regarding the analysis of workplace segregation, the data set has two key advantages over most other data sets used for this type of analysis. First, I am able to follow workers, and their co-workers, over time. This is important as it allows me to investigate how ethnic segregation changes for a given worker over his or her time in the German labour market (see Section 4.5). Second, the data provide information on every worker in every establishment. This allows an accurate calculation of the ethnic composition of each establishment's workforce and ensures that the findings are representative for both establishments and workers. ${ }^{9}$

Since 1999, the German social security records also include a variable indicating a worker's municipality of residence which allows an investigation of the extent of residential segregation. At the end of 2008, Germany was divided into 12,218 such municipalities, with an average working-age population of around 6,700. They are thus roughly comparable to U.S. census tracts, the primary unit of analysis used to study residential segregation in the U.S. context. ${ }^{10}$

My analysis is restricted to workers aged between 15 and 64 and excludes workers who are in marginal part-time employment. ${ }^{11}$ When studying changes in segregation over time, I focus on the years 1980, 1990, 2000, and 2008 (except in Section 4.5). It is important to note that in the years 2000 and 2008, the sample refers to the whole of Germany whereas for the years before, all indices are calculated for West Germany only (the part that used to be the Federal Republic of Germany). I opted for this approach rather than the alternative of restricting the sample to West Germany throughout the observation period

\footnotetext{
${ }^{9}$ Many existing sample-based data sets oversample large establishments and only identify a (random) subset of workers in each establishment. For small units such as establishments, such random sampling of a subset of workers may introduce a bias into the standard segregation measures used in this paper (see Rathelot, 2012).

${ }^{10}$ Although a finer distinction would arguably be preferable for the analysis of residential neighbourhood segregation, for example something comparable to census blocks or block groups as in Bayer et al. (2008), the social security records are currently the only data available for Germany that allow a nationwide analysis of residential segregation by ethnicity. Note also that the data only allow an assessment of the residential segregation of the subgroup of workers who are currently employed in jobs that are subject to social security contributions. If unemployed immigrants are more likely to live in more segregated municipalities, then the estimates will be a lower bound of the overall residential segregation in Germany.

${ }^{11}$ Workers in marginal part-time employment have only been included in the social security records since 1999 and are therefore excluded to ensure consistency across years.
} 
because the focus of the paper is primarily on providing a comprehensive description of the extent of ethnic segregation at different points in time, with a special emphasis on the most recent observation in 2008. When appropriate, I will, however, provide specific figures for West Germany only in order to allow an assessment of the long-run development of segregation in this part of Germany.

Table 1 reports some summary statistics of the sample. For 1980, the sample comprises slightly more than 20 million workers, who are employed in around 1.4 million establishments. Of these workers, $9.5 \%$ have foreign citizenship. I refer to these as immigrant workers. By 2008, the number of immigrant workers in the sample has decreased by 206,194 and their share in the workforce to $6.7 \%$, the latter primarily due to the joining of East Germany which had a substantially lower share of immigrants than West Germany at the time of unification in 1990. The largest individual immigrant groups in 2008 originate from Turkey (26.5\%), Former Yugoslavia (13.7\%), and Italy (9.7\%). However, as column (5) shows, the composition of the immigrant population in Germany is changing, shifting from traditional guest worker countries towards immigrants from Central and Eastern Europe, particularly Poland and the Former Soviet Union. Immigrant workers, in particular those from Turkey, Yugoslavia, Italy, and Greece, are considerably less educated than German workers. Overall, about $12.4 \%$ of German workers have no post-secondary education (labeled as low-educated), compared with $32.8 \%$ of immigrant workers. The share of workers with a university degree (labeled as high-educated) is $13.6 \%$ for German, but only $9.1 \%$ for immigrant workers. Note that more than $80 \%$ of establishments in Germany are small, employing less than 10 employees. Being able to observe these establishments in the data is therefore vital to obtain a representative picture of the overall German labour market.

\section{Measuring Segregation}

There are a number of different measures in the economic and sociological literature that have been used to assess the extent of segregation between different groups (see, for instance, Massey and Denton, 1988, Cutler et al., 1999, or Iceland et al., 2002, for a discussion of these measures). In this study, I consider two of these measures: the tradi- 
tional index of dissimilarity proposed by Duncan and Duncan (1955), and the index of co-worker/co-resident segregation used by, for example, Hellerstein and Neumark (2008).

\subsection{The Index of Dissimilarity}

The index of dissimilarity (or Duncan index) is the most widespread measure of segregation or dissimilarity (see, e.g. Iceland et al., 2002). For illustration, suppose we are interested in the segregation between German workers and immigrant workers, irrespective of the latter's citizenship. The index is then calculated as follows:

$$
\mathrm{ID}^{O}=\text { index of dissimilarity }=1 / 2 \sum_{i=1}^{N}\left|\frac{\text { Immigrant }_{i}}{\text { Immigrant }_{\text {total }}}-\frac{\text { German }_{i}}{\text { German }_{\text {total }}}\right| \cdot 100,
$$

where $i$ denotes the unit of analysis, either establishments or municipalities. The superscript " $O$ " refers to the observed (rather than the random) index; see explanation below. This index relates the share of the overall immigrant workforce that works in a particular establishment (or lives in a particular municipality) to the share of the overall German workforce that works in the same establishment (or lives in the same municipality). The index ranges from 0 (no segregation) to 100 (complete segregation), and can be interpreted as the percentage of immigrant workers that would have to move to different establishments (or municipalities) in order to produce an even distribution relative to native workers. Note that one property of the index of dissimilarity is that it is scale invariant, so that an increase in the number of immigrants does not lead to a change in the measured index as long as the new immigrants are allocated to establishments (or regions) in the same proportions as the original immigrant population. However, such an increase in the number of immigrants would imply that each individual immigrant worker is now surrounded by relatively more other immigrants, which, arguably, should be reflected in a higher degree of segregation. For that reason, as well as to ensure comparability with some of the most relevant existing studies in the literature, I also consider the index of co-worker/co-resident segregation as an alternative measure of segregation. 


\subsection{The Index of Co-worker/Co-resident Segregation}

The index of co-worker/co-resident segregation is based on the shares of co-workers/coresidents with which an individual worker works in the same establishment or lives in the same municipality that belong to specific ethnic groups. ${ }^{12}$ Consider again the segregation between German and immigrant workers across establishments. In a first step, I calculate for each immigrant and German worker in the data the percentage of his or her co-workers that belong to the group of immigrants. Note that I exclude the worker him- or herself from the calculation so that the analysis only covers establishments that employ at least two workers. ${ }^{13}$ In a second step, I average these percentages separately for immigrant and German workers in the data. Following the notation adopted by Hellerstein et al. (2007), I denote these averages by $H_{H}$ and $W_{H}$, respectively. The "isolation index" $H_{H}$ shows the average percentage of immigrant workers' co-workers who are from an immigrant group, while the "exposure index" $W_{H}$ shows the average percentage of German workers' co-workers who are from an immigrant group. The difference between the two, $I C S^{O}=H_{H}-W_{H}$, measures the extent to which immigrant workers are more likely to work with other immigrant workers than German workers are. The superscript "O" indicates, as before, that this measure captures observed segregation in the data. If all immigrant workers only worked with other immigrant workers, then $H_{H}=100$, $W_{H}=0$ and $I C S^{O}=100$, and the two groups of workers would be fully segregated. In contrast, if the percentage of co-workers that are from an immigrant group were the same for immigrant and German workers, then $H_{H}=W_{H}$ and $I C S^{O}=0$, and there would be no co-worker segregation. The index of observed co-resident segregation is computed accordingly, but using municipalities instead of establishments as the units for which isolation and exposure indices are being calculated.

\footnotetext{
${ }^{12}$ Originally, this index was used to describe workplace segregation and was hence appropriately called "index of co-worker segregation". Since I extend the use of this index to residential segregation, I added the reference to "co-residents".

${ }^{13}$ As Hellerstein and Neumark (2008) point out, the exclusion of each worker him- or herself ensures that if workers were randomly assigned to establishments, the unconditional co-worker segregation index would be zero as well as invariant to the sizes of the establishments in the sample.
} 


\subsection{Random Segregation}

As is well known, some segregation may occur even if workers were randomly assigned to different establishments (municipalities), especially if these are small. To take this into account, I follow Carrington and Troske (1997) and calculate a measure of the two segregation indices that would be observed under random allocation. For this purpose, I assign each worker in the data randomly to one of the establishments (municipalities) and then compute the two segregation indices in the same way as described before. I do this repeatedly and take the average of the generated indices, which I denote by $I D^{R}$ and $I C S^{R}{ }^{14}$ The difference $I D^{O}-I D^{R}\left(I C S^{O}-I C S^{R}\right)$ represents segregation that goes beyond that occurring under random allocation. Scaling this measure by the maximum possible non-random segregation, the effective (or systematic) dissimilarity and co-worker/co-resident segregation indices are given by:

$$
I D=\frac{I D^{O}-I D^{R}}{100-I D^{R}} \cdot 100 \text { and } \quad I C S=\frac{I C S^{O}-I C S^{R}}{100-I C S^{R}} \cdot 100
$$

\subsection{Conditional Segregation}

Part of the reason why immigrant workers may be more likely to work (live) with each other than with native Germans could be that they have different characteristics than the latter, and workers of the same characteristics are more likely to work (live) together in the same workplace (municipality), independent of their group affiliation (see, e.g., Saint-Paul, 2001). For example, if immigrant workers were predominantly low-skilled and establishments had either a 100\% low- or a 100\% high-skilled workforce, then lowskilled immigrant workers would tend to cluster in the same establishments - those that require low-skilled workers - and we would observe positive segregation. This segregation, however, would be largely due to the different skill composition of the two groups rather than any ethnicity-driven tendency to cluster in the same establishments. ${ }^{15}$ To deal with

\footnotetext{
${ }^{14}$ Unless stated otherwise, I run 30 simulations for each random segregation measure. For an analytical way to calculate the random co-worker/co-resident segregation index see Åslund and Skans (2009). Note that the random segregation index is typically not computed for the index of dissimilarity.

${ }^{15}$ Bayer et al. (2004) find that differences in sociodemographic characteristics, in particular in terms of eduction, income and language skills, explain a sizeable fraction of residential segregation by race in the San Francisco Bay Area in 1990.
} 
this issue, I again follow the literature (e.g. Hellerstein and Neumark, 2008, or Åslund and Skans, 2010) and compute so-called conditional segregation measures. The calculation of these conditional measures differs from the original procedure only in the way the random segregation measures are calculated. Rather than allocating workers randomly to establishments, the allocation to establishments now takes place within the particular set of characteristics on which the researcher wants to condition. For example, if one wants to take account of the fact that the immigrant workforce has a lower share of women and is, on average, less educated than the native workforce, then the conditioning would be on gender and education and workers are randomly allocated to establishments within the subsamples defined by all possible interactions of gender and educational attainment. If an establishment has, for example, two male workers with low education and one female worker with high education, then two male workers with low education and one female worker with high education will be randomly allocated to that establishment. While the unconditional random segregation indices will be zero in large enough samples and units of analysis, this does not hold for the conditional random indices if the characteristics of immigrant workers differ from those of native workers. This in turn affects the overall measure of effective segregation.

\section{Results}

\subsection{Current Workplace and Residential Segregation}

Table 2 shows the extent of workplace and residential segregation in Germany in the year 2008. Panel A reports results based on the index of dissimilarity and Panel B results based on the index of co-worker/co-resident segregation. I first report the observed segregation index, then the random segregation index, and finally the effective segregation index. The first column shows the unconditional segregation measures at the establishment level. The observed distribution of workers across establishments leads to a dissimilarity index of 58.1. However, not all of this segregation is systematic. If workers were randomly allocated to establishments, the dissimilarity index would amount to 28.6. Taking account of this random segregation, I calculate the effective index of dissimilarity to be 41.3, 
indicating that about $40 \%$ of immigrant workers would have to move in order to achieve an even distribution.

The results in Panel B show that, on average, 23.6\% of immigrant workers' co-workers are also immigrant workers. In contrast, only $5.5 \%$ of German workers' co-workers are immigrant workers, leading to an observed co-worker segregation index of 18.1. Under random allocation of workers to establishments, and in the unconditional case, the average share of both immigrant and German workers' co-workers who are immigrant workers has to be the same (and equal to the overall immigrant share in the workforce), and hence random segregation equal to zero. The effective co-worker segregation index in Germany in 2008 is therefore 18.1, which is comparable in magnitude to what Hellerstein et al. (2007) find for Black-White (21.8) but lower than what they find for Hispanic-White (34.7) workplace segregation in the U.S. in the year 2000. It is also comparable to the estimate reported by Åslund and Skans (2010) for immigrant establishment level segregation in Sweden in the year 2002 (14.6). ${ }^{16}$

How much of the measured workplace segregation can be explained by differences in the regional distribution and in the skill structure between immigrant and German workers? Immigrants tend to settle in different types of locations than natives, particularly larger cities, and are overall less skilled than the native population. In an unconditional analysis, this would lead to some degree of measured segregation, even if within these locations and skill groups immigrants were perfectly integrated. In columns (2) to (4) of Table 2, I therefore report conditional segregation indices. As discussed in the previous section, this conditioning does not affect the observed segregation measures, but leads to changes in the indices that would occur under random allocation of workers to establishments. In a first step, I condition only on the region (county) in which a worker is working. This leads to a significant reduction in both segregation indices, with the dissimilarity index dropping from 41.3 to 29.0 and the co-worker segregation index dropping from 18.1 to 15.9. In column (3), I additionally condition on gender and education, distinguishing between four education groups. This reduces both indices further, to 25.6 and 14.7, respectively. If I also condition on the industry in which a worker is working, distinguishing between 13 broad industries, both indices drop even more. However, over-

\footnotetext{
${ }^{16}$ Own calculations, based on Table 2 in their paper.
} 
all, differences in the regional distribution and observable skills between immigrant and native workers can explain no more than $49 \%$ (index of dissimilarity) or $27 \%$ (index of co-worker segregation) of the observed establishment level segregation. I conclude from these findings that segregation of immigrant workers across establishments is substantial, even within region-, skill-, gender-, and industry-groups.

Columns (5) to (8) show the corresponding analysis for residential segregation. Both the unconditional dissimilarity index and the unconditional co-resident segregation index are substantially lower than the corresponding indices with respect to the workplace. Conditioning on the broader geographical region, gender, education and industry, again leads to a reduction of the two indices similar in relative magnitude to the reduction when moving from column (1) to column (4). ${ }^{17}$ Comparing the two levels of segregation shows that, in Germany, workplace segregation is substantially more pronounced than residential segregation.

In what follows, I will focus on indices that condition on region, gender and education. This is because workers, once they have entered the labour market, are relatively unlikely to move to another region or change their education (and gender). Workers' industries (and other potential conditioning variables such as occupations), on the other hand, are endogenous and may be affected by a worker's experience of workplace and residential segregation. Finally, I will only report the effective segregation indices and refrain from reporting their standard deviations. As Table 2 shows, due to the large sample size, these standard deviations, computed from the 30 simulations of the random segregation indices, are negligible in magnitude.

\subsection{Segregation Over Time and Across Subgroups}

In Table 3, I document how ethnic segregation has developed over time and how it varies across different subgroups of the immigrant population. The first row in each panel illustrates that both workplace and residential segregation have been relatively stable in Germany over the last three decades. While workplace segregation decreased slightly from

\footnotetext{
${ }^{17}$ Note the difference between the conditioning variable "region", which corresponds to one of Germany's 413 counties, and the unit of observation in the residential segregation analysis, which is the municipality where an individual worker lives. Each county in Germany is made up of, on average, around 30 municipalities.
} 
31.4 to 25.6 (dissimilarity index) and from 15.4 to 14.7 (index of co-worker segregation), residential segregation increased from 14.3 to 15.4 according to the index of dissimilarity and decreased from 5.0 to 4.5 according to the index of co-resident segregation. ${ }^{18}$

The results in Table 3 further show, that in terms of workplace segregation there is a clear pattern with respect to the skill level of the workers: low-educated workers are far more segregated than high-educated workers. For example, while the index of co-worker segregation is 15.9 for those without post-secondary education in 2008, it is 11.7 for those with post-secondary education, and 5.8 for those with college education. This pattern may be a reflection of the generally more intensive use of friends and relatives in the job search process among low-skilled workers (see, for example, Borjas, 1998, Ioannides and Loury, 2004, and Wahba and Zenou, 2005). If friends and relatives belong predominantly to the same ethnic group, this could lead to the particularly pronounced clustering of lowskilled immigrant workers across establishments. Interestingly, there is no such pattern with respect to residential segregation. Here both indices show that medium-educated immigrants are slightly more segregated from native Germans than both low- and higheducated immigrants.

Finally, Table 3 shows the two segregation measures separately for 13 different immigrant groups. ${ }^{19}$ Focussing on the year 2008 and the extent of workplace segregation, both indices indicate that Asians and Turks are the two most segregated groups with an index of dissimilarity of 40.8 and 37.8, and an index of co-worker segregation of 15.2 and 12.8, respectively. When studying ethnic minority groups separately, two important trends are discernible. First, for most traditional guest worker countries, workplace segregation has decreased substantially between 1980 and 2008. In contrast, for the immigrant groups that arrived more recently, for example from Poland and the Former Soviet Union, workplace segregation has increased appreciably. Of course, the group of Poles and Russians living in Germany in 1980 was a relatively small and selected group of individuals. In many cases, both size and composition of the immigrant groups listed in Table 3 have

\footnotetext{
${ }^{18}$ The corresponding indices for West Germany only in the years 2000 and 2008 are very similar: with respect to workplace segregation, the index of dissimilarity is 25.2 and the index of co-worker segregation 14.2 ; with respect to residential segregation, the index of dissimilarity is 15.8 and the index of co-resident segregation 4.5 in 2008.

${ }^{19}$ For the co-worker/co-resident segregation index, this means that the index now reflects systematic differences in the probability of working with co-workers of a particular nationality (or nationality group) between immigrants of the same nationality and German workers.
} 
changed significantly between 1980 and 2008 so that comparisons across different years are problematic. I will address this issue more directly in Section 4.5, where I exploit the longitudinal dimension of the data and analyze how workplace segregation changes over time for a given group of individuals.

In terms of residential segregation, three groups stand out when segregation is measured using the dissimilarity index: Turks, Greeks and African immigrants with indices of 21.1, 27.5, and 22.3, respectively, in 2008. These groups also show a relatively high degree of segregation based on the co-resident segregation index; however, based on this measure, by far the most residentially segregated group of workers are workers from other Western European countries, with an index of 10.3 .

Table 4 shows the extent of workplace segregation within different industries. ${ }^{20}$ To obtain the reported measures, I compute the random segregation measures by randomly allocating all workers who work in a given industry to the different establishments operating within that same industry, conditional on region, gender and education. The results show, that ethnic segregation is particularly pronounced in three sectors of the economy: agriculture and mining, construction, and other services, where the latter includes mostly low-skill intensive industries such as the hotel and restaurant sector and the hairdressing industry. Both in agriculture and mining and in construction, today's high levels of segregation are the result of long-term trends starting around the year 1990. The one sector where there has been a substantial decline in workplace segregation is public administration, with the dissimilarity index dropping from 31.1 to 16.4 and the co-worker segregation index dropping from 12.6 to 5.4 between 1980 and 2008 .

\subsection{Segregation Within Workplaces}

The evidence presented so far shows that ethnic segregation, in particular across workplaces, is endemic in the German labour market. However, it may well be that even in establishments with a mixed workforce, immigrant and native German workers are segregated by skill. For example, it could be that all high skill jobs in an establishment are filled by native German workers and all low skill jobs by immigrant workers, and that

\footnotetext{
${ }^{20}$ For a time-consistent definition of the different industries, I use the correspondence tables constructed and described by Eberle et al. (2011) to translate the w03 industry classification used in recent years in the data into the w73 industry classification used up to the year 2002.
} 
for that reason there is relatively little interaction between these groups within the same establishment. To assess the possibility of within-establishment segregation, I calculate the index of co-worker segregation under three different scenarios regarding the degree of interaction between workers of different skill types within establishments. ${ }^{21}$ "Full interaction" means that every worker is assumed to interact in the same way with any other worker, irrespective of the skill type of the other worker relative to his or her own type. This assumption underlies all co-worker segregation indices reported so far. "No interaction", in contrast, assumes that workers only interact with other co-workers of the same skill type. Finally, "some interaction" is an intermediate case where I assign different weights to the intensity of interaction between different skill types based on their distance from each other. ${ }^{22}$

Table 5 shows the corresponding results, using two different measures of the workers' skills, either based on educational attainment or on being a blue-collar or white-collar worker. The first column shows some mild evidence for within-establishment segregation according to both skill type measures, with the index of co-worker segregation increasing from 14.7 in the case of full interaction to 15.1 (education) and 16.4 (blue vs. white) in the case of no interaction, respectively.

One would expect within-establishment segregation to be more important in large establishments than in small ones. In the remaining columns, I therefore break down the analysis by establishment size, distinguishing between very small establishments (less than 10 employees), small establishments (10-49 employees), medium-sized establishments (50-499 employees), and large establishments (at least 500 employees). Note, that ethnic segregation is much more pronounced in small establishments than in large establishments, with a steady decline of the co-worker segregation index from 31.2 for very small establishments to 17.7 for small establishments, 11.2 for medium-sized establishments, and 5.3 for large establishments in the full interaction scenario. Allowing the

\footnotetext{
${ }^{21}$ I focus on the index of co-worker segregation because unlike the index of dissimilarity, this index is directly based on interactions among co-workers.

${ }^{22}$ To be precise, let wXY be the weight assigned if a given worker's skill level is $\mathrm{X}$ and his or her co-worker's skill level is Y. If skill groups are defined by educational attainment (4 groups, $1=$ no postsecondary education, $2=$ post-secondary education, $3=$ college education, and $4=$ unknown education), I assign the following weights: $\mathrm{w} 11=2 / 3, \mathrm{w} 12=2 / 9, \mathrm{w} 13=0, \mathrm{w} 14=1 / 9 ; \mathrm{w} 21=1 / 9, \mathrm{w} 22=2 / 3, \mathrm{w} 23=1 / 9$, $\mathrm{w} 24=1 / 9 ; \mathrm{w} 31=0, \mathrm{w} 32=2 / 9, \mathrm{w} 33=2 / 3, \mathrm{w} 34=1 / 9 ;$ and $\mathrm{w} 41=1 / 9, \mathrm{w} 42=1 / 9, \mathrm{w} 43=1 / 9, \mathrm{w} 44=2 / 3$. If skill groups are defined by blue- and white-collar occupations ( 2 groups), I assign a weight of $2 / 3$ if both workers belong to the same occupational group, and $1 / 3$ if they belong to different occupational groups.
} 
degree of interaction between workers of different skill levels to vary within establishments does not affect the index for very small establishments (column (2)), implying that here immigrant and native workers are not segregated based on their education or blue- and white-collar status. For large establishments, in contrast, the increase in the two indices is more substantial, from 5.3 in the scenario of full interaction to 6.6 and 8.0 in the scenario of no interaction, respectively, pointing towards some degree of within-establishment segregation of immigrants and natives.

\subsection{Segregation and Language}

So far, I have almost exclusively reported measures of segregation between native and immigrant workers, irrespective of the latter's particular citizenship. But many of the existing theories that could explain the clustering of immigrant workers in a particular set of establishments, such as the existence of productivity spillovers or the importance of job search networks, would predict that an individual from a specific ethnic group is more likely to work with individuals from the same group than with those from other ethnic groups. That is, one would expect Turkish workers to predominantly work with other Turkish workers, Polish workers with other Polish workers, etc.

I investigate this issue in Table 6, which shows the effective index of co-worker segregation, conditional on region, gender and education, for each possible pair of immigrant groups. I focus on the co-worker segregation index because it is a more natural measure of an individual worker's exposure to other groups of workers. ${ }^{23}$ For cross-country comparisons, the way to read this table is horizontally. For example, the first row refers to the probability of working with German co-workers. Each cell in this row gives the difference between the probability of German workers working with German co-workers and the probability of the type of worker given in the column heading working with German co-workers (adjusted for random segregation and conditional on region, gender and education). Within rows, the magnitudes of the segregation indices are comparable, with a low value indicating an ethnic minority group that is similar to the group given in the first column in its propensity to work with workers of the latter group's nationality.

The first key insight from the table is that there is segregation not only between

\footnotetext{
${ }^{23}$ Using the index of dissimilarity instead leads to qualitatively very similar patterns.
} 
immigrant groups and native German workers, but also between immigrant groups of different nationality. For instance, Italian workers are similarly segregated from Turkish (8.0) and Polish workers (8.1) as they are from German workers (8.5). Croatian workers are as segregated from Greek (3.5) and Russian workers (3.7) as they are from German workers (3.8). A simple preference of (presumably mostly German) employers for German workers as opposed to immigrant workers is therefore unlikely to be the underlying reason for the clustering of immigrant workers in particular establishments. ${ }^{24}$

A second important insight from Table 6 is that a common language background is a key determinant of ethnic segregation across establishments. The group with which German workers are the least segregated are Austrian workers with a co-worker segregation index of only 3.2, by far the lowest of all indices across the eighteen groups. Note that this is not due to the fact that Austrians are more similar to Germans in terms of their observable skills than most other immigrant groups since the reported indices are conditional on educational attainment (as well as gender and region). Similarly, workers from Serbia and Montenegro are the least segregated from Bosnians (3.0) and Croatians (4.2), who all speak Serbo-Croatian, and Russians are the least segregated from other Russian-speaking immigrants from the Ukraine, Belarus, Kazakhstan, and Kyrgyzstan (0.7), all of which I have aggregated into one category due to the relatively small sample sizes.

The important role of language is consistent with both productivity spillovers between workers, where proficiency in the language of other co-workers increases a worker's own productivity, and language-based job search networks, where workers from different countries of origin belong to the same network if they share the same language. While an empirical separation of the two explanations is beyond the scope of this paper, Dustmann et al. (2011) provide empirical evidence for Germany that the clustering of workers of the same ethnicity in particular establishments is likely due to the widespread use of referrals on behalf of co-nationals.

\footnotetext{
${ }^{24}$ Unfortunately, the data do no include information on the owners of the establishments and their ethnicities, which would allow a more detailed analysis of the link between an employer's nationality and that of his or her workforce (see Giuliano et al., 2009, and Åslund et al., 2009).
} 


\subsection{Segregation and Assimilation}

If productivity spillovers or social networks are responsible for the observed workplace segregation, one would expect immigrants to become less segregated over time as they adapt to the German labour market and have to rely less on their native language for communication with their co-workers and on their informal networks for job search purposes. I investigate this issue by means of Figure 1, whose left hand side panel depicts the effective dissimilarity index for the overall group of immigrants by entry cohort and year. Cohorts of immigrant workers are defined by the year in which I first observe them in the social security records. For better readability, Figure 1 only displays the profiles of every other entry cohort. To avoid a changing composition of the set of workers in a given cohort due to emigration or exits from the labour force, I condition on all workers being employed (and hence observed in the data) in the final year of observation, $2008 .^{25}$

The depicted segregation profiles show, that for all immigrant cohorts, ethnic workplace segregation decreases quite smoothly with the time spent in Germany. The first observable cohort, for example, entered the German labour market in 1976 with a dissimilarity index of 33.6 which then steadily decreased over the next 32 years to a level of 12.1 in 2008. For this cohort, as well as many of the subsequent cohorts, there has been a significant reduction in the degree of segregation from the native German population. However, given the flattening out of the profiles in more recent years, a full assimilation in terms of workplace choice does not seem to be likely, even in the very long-run. What is more, while the extent of workplace segregation in the year of entry has been relatively constant over time (at least since 1985 and with the exception of the 1998 cohort), recent immigrant cohorts appear increasingly less likely to be able to reduce their segregation from the native German workforce over time. If workplace segregation reflects the state of immigrants' integration in the German labour market, this development is reason for concern. $^{26}$

\footnotetext{
${ }^{25}$ In the absence of better information, the distinction between different cohorts based on the first year of appearance in the data and the conditioning on employment in the final year of observation serve as proxies for the year of arrival in Germany and for having remained in Germany up to 2008, respectively. Lubotsky (2007) follows a similar approach to deal with the problem of selective emigration and circulatory migration for the estimation of immigrants' earnings profiles in the United States.

${ }^{26}$ I have also computed corresponding profiles for the four largest individual immigrant groups in Germany (Turkey, Former Yugoslavia, Italy and Greece), with very similar patterns. This finding rules out that compositional changes in terms of origin are the main drivers of the observed assimilation profiles.
} 
Figure 1: Workplace Segregation and Relative Wages over Time
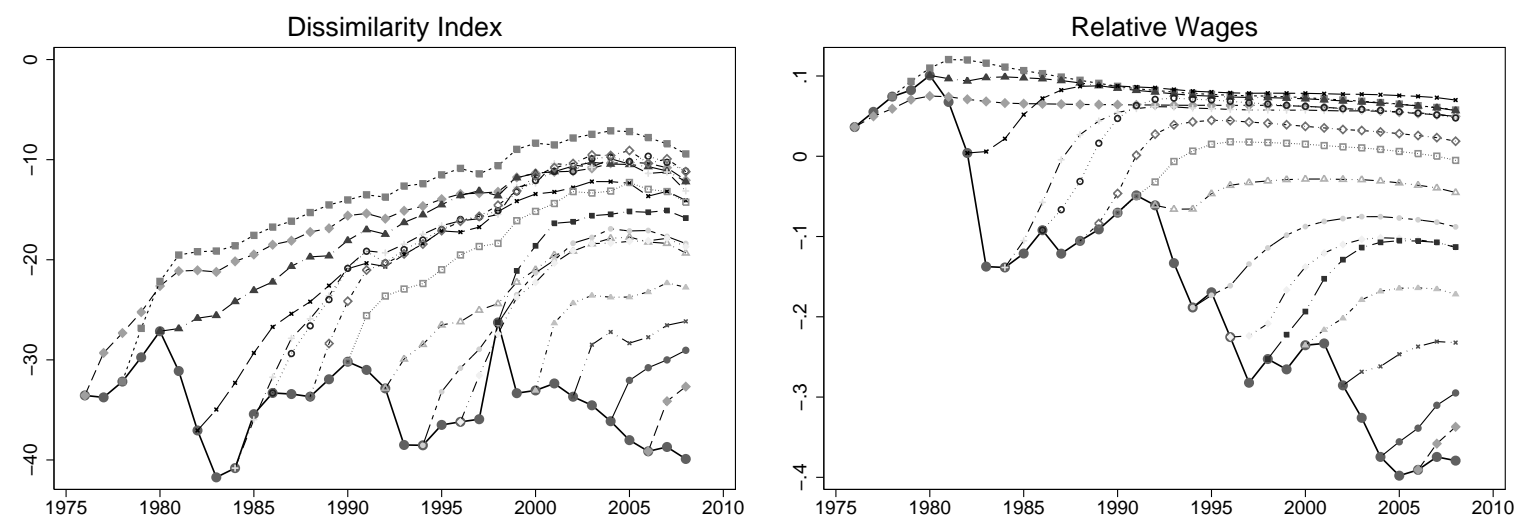

Note: Values depicted show the effective index of dissimilarity conditional on region, gender and education (multiplied by -1) in the left panel and relative wages for different immigrant cohorts in the right panel. Immigrants are included in the sample for both panels conditional on being observed in the data in 2008.

The patterns shown in the left hand side panel of Figure 1 are reminiscent of the profiles one obtains in a traditional study of immigrants' wage assimilation. The right hand side panel of Figure 1 shows the corresponding, semiparametrically estimated, relative wage profiles, controlling for a quartic in age, and education, gender, and region dummies. ${ }^{27}$ In contrast to workplace segregation, there has been a dramatic deterioration of immigrants' relative wages at the time of entry into the German labour market over the last few decades (compare also Fertig and Schurer, 2007, and Gundel and Peters, 2007). However, after entry, workplace segregation and relative wages evolve in a similar fashion. While it is obviously not possible to deduce a causal relationship from these patterns, it is clear that improvements in the relative wage position of the immigrant population go hand in hand with less segregation from native workers across establishments. One reason could be that immigrants, over time, move to high productivity firms and these are, at the same time, firms with a larger native German workforce. A detailed analysis of the precise mechanism driving the co-movement of workplace segregation and relative wages is left for future research. The main conclusion to be taken from Figure 1 is that immigrants' workplace segregation decreases over time spent in the German labour market and that it can serve as a valuable indicator for the degree of immigrants' economic

\footnotetext{
${ }^{27}$ Specifically, for each year 1976 to 2008 , I estimate the model $\ln w_{i}=\alpha^{\prime} C_{i}+\beta_{1} a g e_{i}+\beta_{2} a g e_{i}^{2}+\beta_{3} a g e_{i}^{3}+$ $\beta_{4} a g e_{i}^{4}+\gamma^{\prime} e d u_{i}+\delta^{\prime}$ sex $_{i}+\eta^{\prime}$ region $_{i}+\varepsilon_{i}$, where $e d u_{i}$, sex $_{i}$ and region $i$ are vectors of education, gender and region dummies, respectively, and $C_{i}$ is a vector of dummy variables indicating an immigrant's entry cohort, with all native Germans in a given year constituting the base category. The right hand side panel of Figure 1 reports the estimated $\alpha$ 's for each immigrant entry cohort.
} 
integration in their host countries' societies.

\section{Conclusion}

By means of two widely used measures of segregation, this paper documents in detail and for the first time the current level of ethnic workplace and residential segregation in Germany as well as the main trends over the last three decades. Based on comprehensive administrative data covering the universe of workers active in the German labour market between 1975 and 2008, I compute a variety of indices of dissimilarity and co-worker/coresident segregation that take account of differences in observable characteristics between the immigrant and native populations and that isolate the systematic component of segregation - the component that goes beyond the level of segregation which would occur under random allocation of workers to establishments or residential locations.

The main findings are that both ethnic workplace and, to a lesser extent, residential segregation are pervasive and persistent in the German labour market. Low-educated workers are substantially more segregated across workplaces than high-educated workers, and immigrants tend to be as segregated from immigrants of other nationalities as from German workers, unless both immigrant groups speak a common language. A simple story of employer discrimination against non-German workers is therefore unlikely to be the driving force behind segregation in Germany. From a dynamic point of view, for a given cohort, ethnic workplace segregation declines with time spent in the labour market, but not at a rate fast enough for it to disappear entirely, especially among more recent cohorts of immigrants. Finally, immigrants' level of workplace segregation is closely linked to their relative earnings position, making it, also in this dimension, an informative measure of their integration in the German labour market.

Future research will have to look more closely at the specific mechanisms that are giving rise to the patterns documented in this paper. Of particular interest in this context should be the dynamic dimension of segregation. Understanding what factors enable or inhibit workers to move to less segregated establishments will allow policy makers to devise appropriate measures to facilitate this process and to foster immigrants' economic integration in their host societies. 


\section{References}

Åslund, O., L. Hensvik, and O. Nordström Skans (2009). Seeking similarity: How immigrants and natives manage at the labor market. CReAM Discussion Paper 32/09.

Åslund, O. and O. N. Skans (2009). How to measure segregation conditional on the distribution of covariates. Journal of Population Economics 22(4), 971-981.

Åslund, O. and O. N. Skans (2010). Will I see you at work? Ethnic workplace segregation in Sweden, 1985-2002. Industrial and Labor Relations Review 63(3), 471-493.

Bauer, T., B. Dietz, K. F. Zimmermann, and E. Zwintz (2005). German migration: Development, assimilation, and labour market effects. In K. F. Zimmermann (Ed.), European Migration, Chapter 7, pp. 197-261. Oxford: Oxford University Press.

Bayer, P., R. McMillan, and K. S. Rueben (2004). What drives racial segregation? new evidence using census microdata. Journal of Urban Economics 56(3), 514-535.

Bayer, P., S. E. Ross, and G. Topa (2008). Place ofwork and place of residence: Informal hiring networks and labor market outcomes. Journal of Political Economy 116(6), $1150-1196$.

Becker, G. S. (1957). The Economics of Discrimination. Chicago: University of Chicago Press.

Borjas, G. J. (1998). To ghetto or not to ghetto: Ethnicity and residential segregation. Journal of Urban Economics 44 (2), 228-253.

Bundesagentur für Arbeit (2004). Arbeitsmarkt 2003. Amtliche Nachrichten der Bundesagentur für Arbeit.

Carrington, W. J. and K. R. Troske (1997). On measuring segregation in samples with small units. Journal of Business \& Economic Statistics 15(4), 402-09.

Carrington, W. J. and K. R. Troske (1998). Interfirm racial segregation and the black/white wage gap. Journal of Labor Economics 16(2), 231-260. 
Chiswick, B. R. and P. W. Miller (1995). The endogeneity between language and earnings: International analyses. Journal of Labor Economics 13(2), 246-288.

Clark, K. and S. Drinkwater (2002). Enclaves, neighbourhood effects and employment outcomes: Ethnic minorities in England and Wales. Journal of Population Economics 15(1), 5-29.

Cutler, D. M. and E. L. Glaeser (1997). Are ghettos good or bad? Quarterly Journal of Economics 112(3), 827-872.

Cutler, D. M., E. L. Glaeser, and J. L. Vigdor (1999). The rise and decline of the american ghetto. Journal of Political Economy 107(3), 455-506.

Cutler, D. M., E. L. Glaeser, and J. L. Vigdor (2008a). Is the melting pot still hot? explaining the resurgence of immigrant segregation. Review of Economics and Statistics $90(3), 478-497$.

Cutler, D. M., E. L. Glaeser, and J. L. Vigdor (2008b). When are ghettos bad? Lessons from immigrant segregation in the United States. Journal of Urban Economics 63(3), $759-774$.

Damm, A. P. (2009). Ethnic enclaves and immigrant labor market outcomes: Quasiexperimental evidence. Journal of Labor Economics 27(2), 281-314.

Duncan, O. D. and B. Duncan (1955, April). A methodological analysis of segregation indexes. American Sociological Review 20(2), 210-217.

Dustmann, C. and A. Glitz (2011). Migration and education. In E. A. Hanushek, S. Machin, and L. Woessmann (Eds.), Handbook of the Economics of Education, Volume 4, Chapter 4, pp. 327-439. Amsterdam: Elsevier-North Holland.

Dustmann, C., A. Glitz, and U. Schönberg (2011). Referral-based job search networks. CReAM Discussion Paper No. 14/11.

Eberle, J., P. Jacobebbinghaus, J. Ludsteck, and J. Witter (2011). Generation of timeconsistent industry codes in the face of classification changes - simple heuristic based on the establishment history panel (bhp). FDZ-Methodenreport 05/2011. 
Edin, P.-A., P. Fredriksson, and O. Åslund (2003). Ethnic enclaves and the economic success of immigrants - evidence from a natural experiment. Quarterly Journal of Economics 118(1), 329-357.

Fertig, M. and S. Schurer (2007). Earnings assimilation of immigrants in germany: The importance of heterogeneity and attrition bias. SOEPpapers No. 30.

Fitzenberger, B., A. Osikominu, and R. Völter (2006). Imputation rules to improve the education variable in the IAB employment subsample. Schmollers Jahrbuch : Journal of Applied Social Science Studies / Zeitschrift fr Wirtschafts- und Sozialwissenschaften 126(3), 405-436.

Giuliano, L., D. I. Levine, and J. Leonard (2009). Manager race and the race of new hires. Journal of Labor Economics 27(4), 589-631.

Gundel, S. and H. Peters (2007). Assimilation and cohort effects for german immigrants. SOEPpapers No. 64.

Hellerstein, J., M. McInerney, and D. Neumark (2007). Changes in workplace segregation in the United States: Evidence from the 1990 and 2000 decennial employer-employee datasets. In S. Bender, J. Lane, K. Shaw, F. Andersson, and T. von Wachter (Eds.), The Analysis of Firms and Employees: Quantitative and Qualitative Approaches, Chapter 5, pp. 163-195. University of Chicago Press.

Hellerstein, J. and D. Neumark (2003). Ethnicity, language, and workplace segregation: Evidence from a new matched employer-employee data set. Annales d'Economie et Statistique 71-72, 19-78.

Hellerstein, J. and D. Neumark (2008). Workplace segregation in the United States: Race, ethnicity, and skill. Review of Economics and Statistics 90(3), 459-477.

Iceland, J., D. H. Weinberg, and E. Steinmetz (2002). Racial and Ethnic Residential Segregation in the United States: 1980-2000. Washington, DC: U.S. Census Bureau.

Ioannides, Y. M. and L. D. Loury (2004). Job information networks, neighborhood effects, and inequality. Journal of Economic Literature 42(4), 1056-1093. 
Lazear, E. P. (1999). Culture and language. Journal of Political Economy 107(S6), S95-S126.

Lubotsky, D. (2007). Chutes or ladders? a longitudinal analysis of immigrant earnings. Journal of Political Economy 115(5), 820-867.

Massey, D. S. and N. A. Denton (1988). The dimensions of residential segregation. Social Forces 67(2), 281-315.

McPherson, M., L. Smith-Lovin, and J. M. Cook (2001). Birds of a feather: Homophily in social networks. Annual Review of Sociology 27, 415-439.

Munshi, K. (2003). Networks in the modern economy: Mexican migrants in the U.S. labor market. Quarterly Journal of Economics 118(2), 549-599.

Musterd, S. (2005). Social and ethnic segregation in europe: Levels, causes, and effects. Journal of Urban Affairs 27(3), 331-348.

OECD (2011). Society at a Glance, 2011. OECD Publications, Paris.

Pellizzari, M. (2010). Do friends and relatives really help in getting a good job? Industrial and Labor Relations Review 63(3), 494-510.

Rathelot, R. (2012). Measuring segregation when units are small: A parametric approach. Journal of Business and Economic Statistics, forthcoming.

Saint-Paul, G. (2001). On the distribution of income and worker assignment under intrafirm spillovers, with an application to ideas and networks. Journal of Political Economy 109(1), 1-37.

Semyonov, M. and A. Glikman (2009). Ethnic residential segregation, social contacts, and anti-minority attitudes in European societies. European Sociological Review 25(6), $693-708$.

Topa, G. (2011). Labor markets and referrals. In J. Benhabib, A. Bisin, and M. O. Jackson (Eds.), Handbook of Social Economics (1 ed.), Volume 1, Chapter 22, pp. 1193-1221. Amsterdam: Elsevier North Holland. 
Wahba, J. and Y. Zenou (2005). Density, social networks and job search methods: Theory and application to Egypt. Journal of Development Economics 78(2), 443-473. 
Table 1: Sample Statistics, 1980-2008

\begin{tabular}{|c|c|c|c|c|c|}
\hline & $\begin{array}{c}(1) \\
1980 \\
\end{array}$ & $\begin{array}{c}(2) \\
1990 \\
\end{array}$ & $\begin{array}{c}(3) \\
2000 \\
\end{array}$ & $\begin{array}{c}4) \\
2008 \\
\end{array}$ & $\begin{array}{c}(5) \\
\text { Change } 1980-2008 \\
\end{array}$ \\
\hline No. of Workers & $20,429,427$ & $21,847,119$ & $26,324,915$ & $25,622,071$ & $25.4 \%$ \\
\hline Share Women (in \%) & 38.6 & 40.7 & 43.4 & 44.5 & 5.9 \\
\hline $\begin{array}{l}\text { Share German (in \%) } \\
\text { of which }\end{array}$ & 90.5 & 91.9 & 93.1 & 93.3 & 2.7 \\
\hline Female & 39.5 & 41.5 & 44.1 & 45.1 & 5.6 \\
\hline Low Education & 27.3 & 18.9 & 13.4 & 12.4 & -14.9 \\
\hline Medium Education & 65.8 & 72.3 & 73.1 & 71.9 & 6.1 \\
\hline High Education & 4.6 & 7.2 & 11.3 & 13.6 & 9.1 \\
\hline Unknown Education & 2.4 & 1.6 & 2.2 & 2.1 & -0.3 \\
\hline $\begin{array}{l}\text { Share Immigrant (in \%) } \\
\text { of which }\end{array}$ & 9.5 & 8.1 & 6.9 & 6.7 & -2.7 \\
\hline Female & 29.9 & 31.7 & 33.6 & 36.0 & 6.1 \\
\hline Low Education & 55.4 & 48.8 & 40.3 & 32.8 & -22.6 \\
\hline Medium Education & 32.6 & 40.5 & 44.2 & 45.1 & 12.5 \\
\hline High Education & 3.1 & 4.2 & 5.4 & 9.1 & 6.0 \\
\hline Unknown Education & 8.9 & 6.5 & 10.1 & 13.1 & 4.1 \\
\hline \multicolumn{6}{|l|}{ Immigrant Origin } \\
\hline Turkey & 30.0 & 32.9 & 28.4 & 26.5 & -3.5 \\
\hline Former Yugoslavia & 17.7 & 17.4 & 15.7 & 13.7 & -3.9 \\
\hline Italy & 15.2 & 10.3 & 10.8 & 9.7 & -5.5 \\
\hline Greece & 6.6 & 5.9 & 5.7 & 4.7 & -1.9 \\
\hline Poland & 0.4 & 2.1 & 3.0 & 4.6 & 4.2 \\
\hline Former Soviet Union & 0.0 & 0.1 & 2.0 & 4.1 & 4.0 \\
\hline Other Western Europe & 19.5 & 18.9 & 17.3 & 15.7 & -3.8 \\
\hline Central and Eastern Europe & 1.1 & 2.1 & 3.2 & 4.9 & 3.9 \\
\hline Africa & 2.0 & 2.5 & 3.8 & 4.0 & 2.0 \\
\hline Central and South America & 0.4 & 0.5 & 0.8 & 1.3 & 0.9 \\
\hline North America & 1.0 & 1.6 & 1.3 & 1.3 & 0.3 \\
\hline Asia & 3.7 & 4.9 & 7.5 & 9.2 & 5.5 \\
\hline Others & 2.5 & 0.8 & 0.5 & 0.4 & -2.1 \\
\hline $\begin{array}{l}\text { No. of Firms } \\
\text { of which }\end{array}$ & $1,396,742$ & $1,535,531$ & $2,063,651$ & $1,990,209$ & $42.5 \%$ \\
\hline Very Small Firms $(<10)$ & 80.6 & 80.8 & 80.6 & 80.6 & 0.0 \\
\hline Small Firms (10-49) & 15.2 & 15.1 & 15.4 & 15.2 & -0.1 \\
\hline Medium Firms (50-499) & 3.9 & 3.8 & 3.8 & 4.0 & 0.2 \\
\hline Large Firms $(>500)$ & 0.3 & 0.3 & 0.2 & 0.2 & -0.1 \\
\hline
\end{tabular}

Note: The table reports descriptive statistics for the years 1980, 1990, 2000 and 2008. Low education workers are workers without post-secondary education. Medium education workers are workers who completed an apprenticeship. High education workers are workers with a university degree. The figures refer to West Germany until 1990 and to West and East Germany thereafter. 


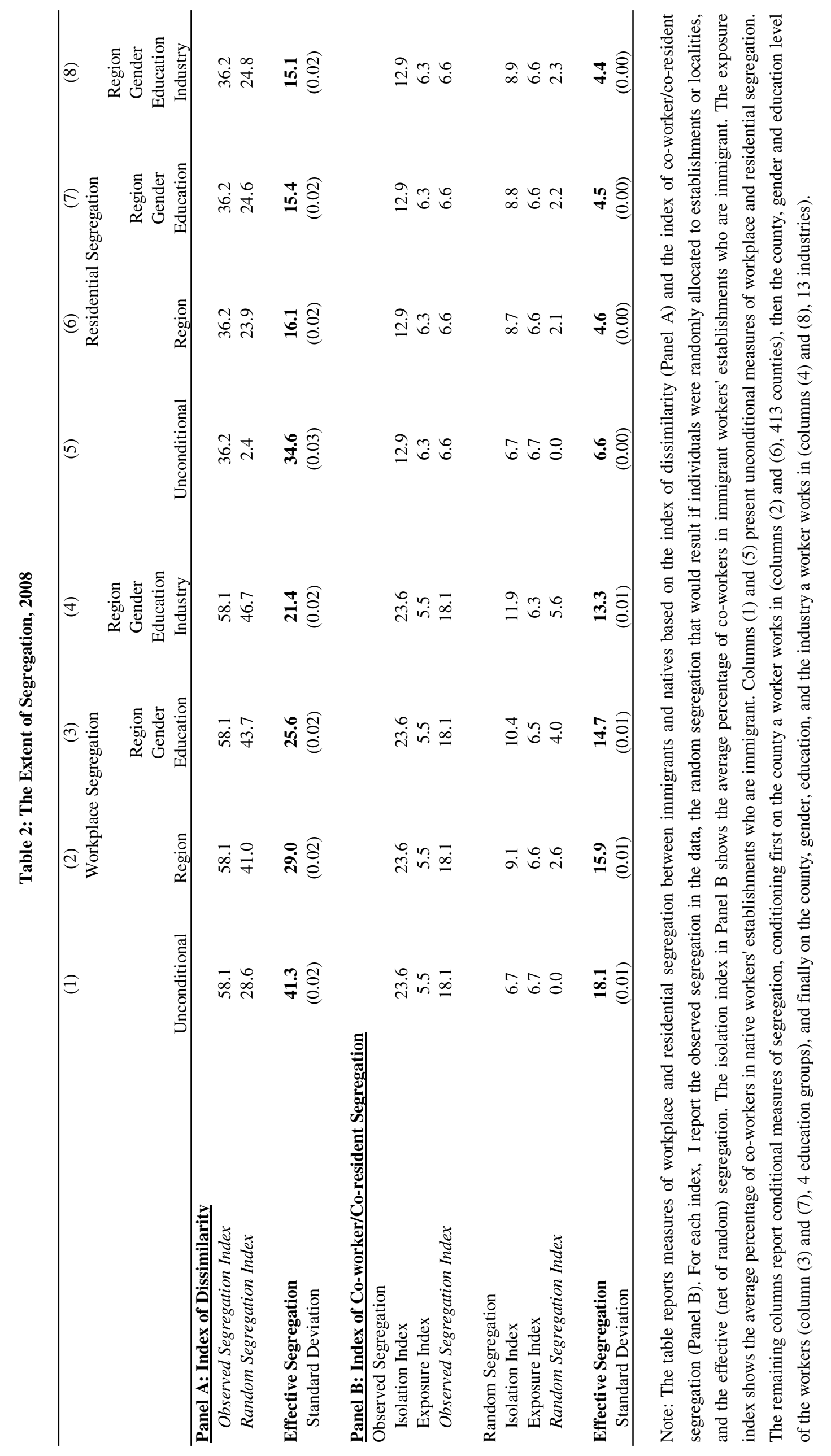


Table 3: Segregation over Time, 1980-2008

\begin{tabular}{|c|c|c|c|c|c|c|}
\hline \multirow[t]{3}{*}{+2} & \multirow{3}{*}{$\begin{array}{c}(1) \\
1980\end{array}$} & \multirow{2}{*}{\multicolumn{2}{|c|}{$\begin{array}{c}(2) \\
\text { Workplace Segregation }\end{array}$}} & \multirow{3}{*}{$\begin{array}{c}(4) \\
2008 \\
\end{array}$} & \multirow{2}{*}{\multicolumn{2}{|c|}{$\begin{array}{cc}(5) & (6) \\
\text { Residential Segregation }\end{array}$}} \\
\hline & & & & & & \\
\hline & & $1990^{\circ}$ & 2000 & & 2000 & 2008 \\
\hline \multicolumn{7}{|l|}{ Panel A: Index of Dissimilarity } \\
\hline All & 31.4 & 27.9 & 26.9 & 25.6 & 14.3 & 15.4 \\
\hline Low Education & 35.1 & 30.3 & 28.9 & 27.7 & 14.6 & 14.6 \\
\hline Medium Education & 28.7 & 25.2 & 23.2 & 21.8 & 15.0 & 16.0 \\
\hline High Education & 22.5 & 17.6 & 16.5 & 18.1 & 10.2 & 13.4 \\
\hline \multicolumn{7}{|l|}{ Immigrant Origin } \\
\hline Turkey & 46.7 & 42.0 & 38.2 & 37.8 & 19.7 & 21.1 \\
\hline Former Yugoslavia & 37.9 & 32.2 & 28.6 & 26.5 & 17.0 & 17.6 \\
\hline Italy & 36.6 & 31.9 & 28.7 & 23.3 & 16.2 & 17.4 \\
\hline Greece & 41.1 & 37.7 & 33.8 & 26.4 & 27.1 & 27.5 \\
\hline Poland & 22.0 & 35.2 & 32.6 & 30.5 & 13.7 & 13.6 \\
\hline Former Soviet Union & 17.8 & 40.4 & 38.4 & 30.9 & 16.2 & 16.9 \\
\hline Other Western Europe & 27.1 & 21.1 & 18.6 & 16.4 & 15.6 & 15.9 \\
\hline Central and Eastern Europe & 15.3 & 21.1 & 30.6 & 29.8 & 9.9 & 11.3 \\
\hline Africa & 35.1 & 30.5 & 34.0 & 35.2 & 19.5 & 22.3 \\
\hline Central and South America & 19.7 & 18.4 & 20.4 & 22.7 & 11.5 & 14.3 \\
\hline North America & 23.1 & 23.7 & 17.2 & 16.7 & 13.2 & 14.7 \\
\hline Asia & 45.9 & 36.4 & 40.4 & 40.8 & 15.5 & 17.7 \\
\hline Others & 15.3 & 14.2 & 20.6 & 20.3 & 10.3 & 9.3 \\
\hline \multicolumn{7}{|c|}{ Panel B: Index of Co-worker/Co-resident Segregation } \\
\hline All & 15.4 & 13.0 & 15.0 & 14.7 & 5.0 & 4.5 \\
\hline Low Education & 16.1 & 13.4 & 15.9 & 15.9 & 4.2 & 3.7 \\
\hline Medium Education & 14.3 & 11.8 & 12.4 & 11.7 & 6.0 & 5.3 \\
\hline High Education & 5.2 & 4.9 & 5.1 & 5.8 & 3.9 & 3.9 \\
\hline \multicolumn{7}{|l|}{ Immigrant Origin } \\
\hline Turkey & 12.0 & 11.5 & 11.3 & 12.8 & 1.2 & 1.2 \\
\hline Former Yugoslavia & 11.5 & 9.3 & 7.3 & 7.5 & 0.9 & 0.8 \\
\hline Italy & 10.6 & 9.3 & 12.0 & 8.5 & 0.6 & 0.6 \\
\hline Greece & 6.1 & 6.9 & 11.8 & 9.8 & 0.8 & 0.7 \\
\hline Poland & 2.5 & 3.5 & 9.2 & 13.1 & 0.2 & 0.3 \\
\hline Former Soviet Union & 2.9 & 1.9 & 4.4 & 3.2 & 0.2 & 0.1 \\
\hline Other Western Europe & 7.7 & 5.7 & 8.8 & 6.6 & 12.6 & 10.3 \\
\hline Central and Eastern Europe & 1.9 & 2.8 & 7.2 & 8.0 & 0.3 & 0.3 \\
\hline Africa & 3.4 & 3.1 & 3.7 & 4.4 & 0.3 & 0.3 \\
\hline Central and South America & 1.2 & 1.4 & 2.1 & 2.3 & 0.0 & 0.1 \\
\hline North America & 3.88 & 6.4 & 5.0 & 4.6 & 0.1 & 0.1 \\
\hline Asia & 8.5 & 10.8 & 12.2 & 15.2 & 0.3 & 0.4 \\
\hline Others & 1.1 & 3.0 & 0.9 & 1.2 & 0.1 & 0.0 \\
\hline
\end{tabular}

Note: The table reports the effective index of dissimilarity (Panel A) and the effective index of co-worker/co-resident segregation (Panel B) between immigrants and natives by industry and education. All indices are constructed conditional on region, gender and education. 
Table 4: Workplace Segregation by Industry, 1980-2008

\begin{tabular}{|c|c|c|c|c|}
\hline & $\begin{array}{c}(1) \\
1980\end{array}$ & $\begin{array}{c}(2) \\
1990\end{array}$ & $\begin{array}{c}(3) \\
2000\end{array}$ & $\begin{array}{c}(4) \\
2008\end{array}$ \\
\hline \multicolumn{5}{|l|}{ Panel A: Index of Dissimilarity } \\
\hline Agriculture and Mining & 31.2 & 30.7 & 32.4 & 35.1 \\
\hline Construction & 23.5 & 19.5 & 26.4 & 31.0 \\
\hline \multicolumn{5}{|l|}{ Manufacturing } \\
\hline low tech. & 25.7 & 22.3 & 22.8 & 22.7 \\
\hline basic & 20.0 & 17.7 & 18.1 & 16.5 \\
\hline high tech. & 18.6 & 17.2 & 16.8 & 13.5 \\
\hline Communications, Transport, and Utilities & 25.4 & 21.9 & 20.2 & 20.1 \\
\hline Wholesale Trade & 25.4 & 23.9 & 22.8 & 22.6 \\
\hline Retail Trade & 11.4 & 12.7 & 15.7 & 16.9 \\
\hline Prof., Medical, and Business Services and FIRE & 27.6 & 27.2 & 27.5 & 25.9 \\
\hline Education and Welfare & 18.1 & 17.9 & 18.0 & 18.2 \\
\hline Public Administration & 31.1 & 28.1 & 20.1 & 16.4 \\
\hline Other Services & 33.0 & 29.9 & 36.2 & 33.8 \\
\hline Missing & 17.5 & 0.9 & -0.2 & 11.7 \\
\hline \multicolumn{5}{|l|}{ Panel B: Index of Co-worker Segregation } \\
\hline Agriculture and Mining & 14.8 & 16.7 & 19.6 & 25.1 \\
\hline Construction & 17.6 & 13.4 & 19.3 & 25.8 \\
\hline \multicolumn{5}{|l|}{ Manufacturing } \\
\hline low tech. & 13.6 & 11.4 & 12.2 & 13.4 \\
\hline basic & 9.3 & 7.5 & 8.1 & 7.3 \\
\hline high tech. & 7.9 & 7.1 & 6.7 & 5.2 \\
\hline Communications, Transport, and Utilities & 11.5 & 9.9 & 10.5 & 11.3 \\
\hline Wholesale Trade & 12.4 & 12.0 & 12.8 & 12.7 \\
\hline Retail Trade & 7.1 & 7.1 & 9.4 & 10.7 \\
\hline Prof., Medical, and Business Services and FIRE & 12.0 & 13.0 & 17.2 & 15.3 \\
\hline Education and Welfare & 7.2 & 7.2 & 7.3 & 6.9 \\
\hline Public Administration & 12.6 & 11.0 & 6.4 & 5.4 \\
\hline Other Services & 29.1 & 24.1 & 29.1 & 26.3 \\
\hline Missing & 7.1 & -0.1 & 0.0 & 11.3 \\
\hline
\end{tabular}

Note: The table reports the effective index of dissimilarity and the effective index of co-worker segregation between immigrants and natives by industry, conditional on region, gender and education. 
Table 5: Workplace Segregation within Establishments by Establishment Size, 2008

\begin{tabular}{|c|c|c|c|c|c|}
\hline & $\begin{array}{c}\text { (1) } \\
\text { All } \\
\text { Establishments } \\
\end{array}$ & $\begin{array}{c}(2) \\
\text { Very Small } \\
\text { Establishments }\end{array}$ & $\begin{array}{c}\text { (3) } \\
\text { Small } \\
\text { Establishments } \\
\end{array}$ & $\begin{array}{c}\text { (4) } \\
\text { Medium } \\
\text { Establishments } \\
\end{array}$ & $\begin{array}{c}\text { (5) } \\
\text { Large } \\
\text { Establishments }\end{array}$ \\
\hline \multicolumn{6}{|l|}{ Education } \\
\hline Full Interaction & 14.7 & 31.2 & 17.7 & 11.2 & 5.3 \\
\hline Some Interaction & 15.1 & 31.3 & 18.0 & 11.5 & 5.8 \\
\hline No Interaction & 15.1 & 31.6 & 18.9 & 11.9 & 6.6 \\
\hline \multicolumn{6}{|l|}{ Blue- vs. White-collar } \\
\hline Full Interaction & 14.7 & 31.2 & 17.7 & 11.2 & 5.3 \\
\hline Some Interaction & 15.4 & 31.5 & 18.3 & 11.9 & 6.1 \\
\hline No Interaction & 16.4 & 31.9 & 19.4 & 13.2 & 8.0 \\
\hline
\end{tabular}

Note: The table reports measures of within-establishment segregation by establishment size based on the effective index of coworker segregation, conditional on region, gender and education. Very small establishments are establishments with less than 10 employees, small establishments are establishments with 10 to 49 employees, medium-sized establishments are establishments with 50 to 499 employees, and large establishments are establishments with at least 500 employees. Full interaction means that every worker interacts in the same way with any other worker, irrespective of the skill type of the other worker relative to one's own type. Some interaction assigns weights to the intensity of interaction between different skill types, with the interaction with a worker of the same type receiving the highest weight (see footnote 22 for details). Finally, no interaction only allows workers to interact with other coworkers of the same skill type. 


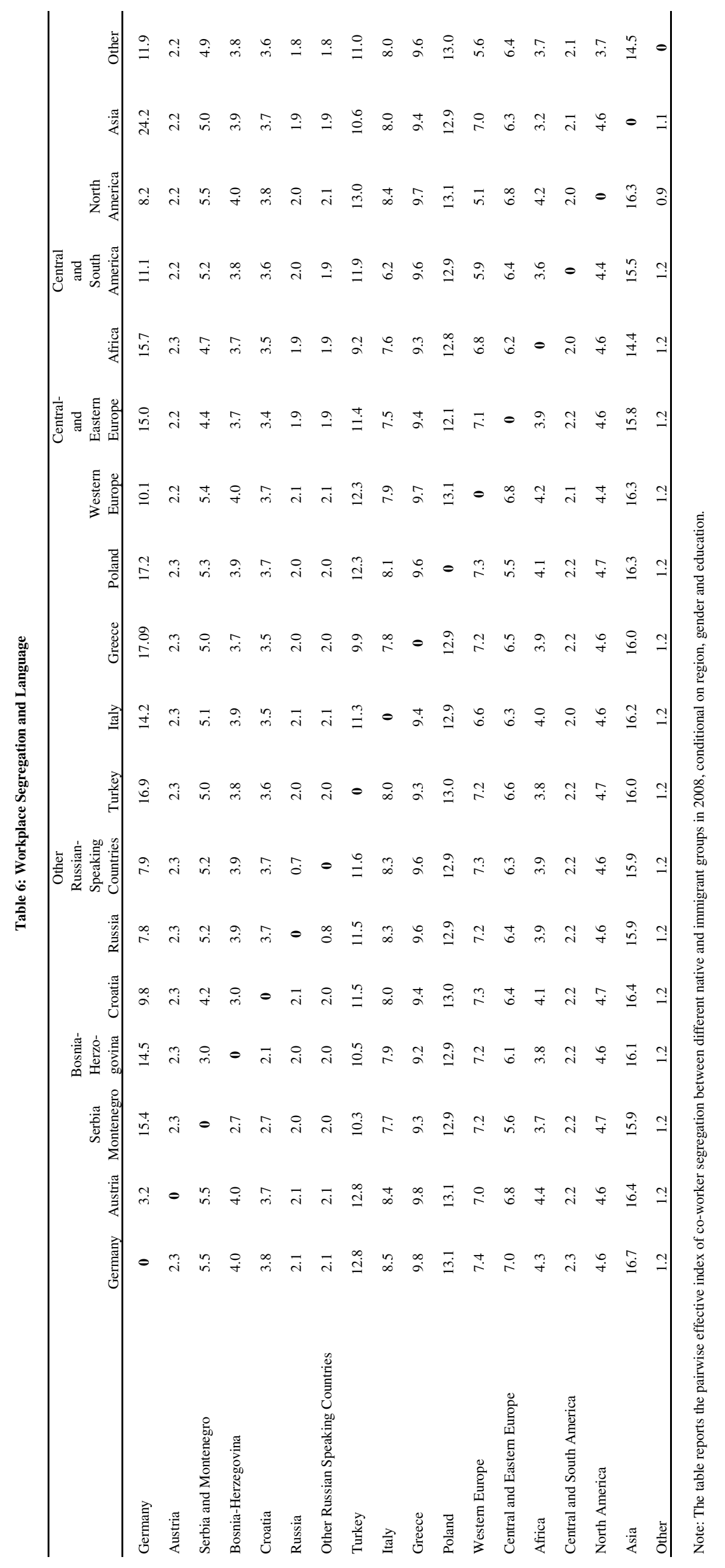

